\title{
Potent inhibition of nitroglycerin bioactivation by diphenyleneiodonium (DIP)
}

Regina Neubauer ${ }^{1}$, Andrea Neubauer ${ }^{1}$, Gerald Wölkart ${ }^{1}$, Christine Schwarzenegger ${ }^{1}$, Barbara Lang ${ }^{1}$, Kurt Schmidt ${ }^{1}$, Michael Russwurm², Doris Koesling², Antonius CF Gorren', Astrid Schrammel', Bernd Mayer ${ }^{1 *}$

From 6th International Conference on cGMP: Generators, Effectors and Therapeutic Implications Erfurt, Germany. 28-30 June 2013

\section{Background}

Aldehyde dehydrogenase-2 (ALDH2) catalyzes vascular bioactivation of the antianginal drug nitroglycerin (GTN) to yield nitric oxide $(\mathrm{NO})$ or a related species that activates soluble guanylate cyclase (sGC), resulting in cGMPmediated vasodilation [1]. Accordingly, established ALDH2 inhibitors attenuate GTN-induced vasorelaxation in vitro and in vivo. However, the ALDH2 hypothesis has not been reconciled with early studies demonstrating potent inhibition of the GTN response by diphenyleneiodonium (DPI) [2], a widely used inhibitor of flavoproteins, in particular NADPH oxidases. We addressed this issue and investigated the effects of DPI on GTN-induced relaxation of rat aortic rings and the function of purified ALDH2.
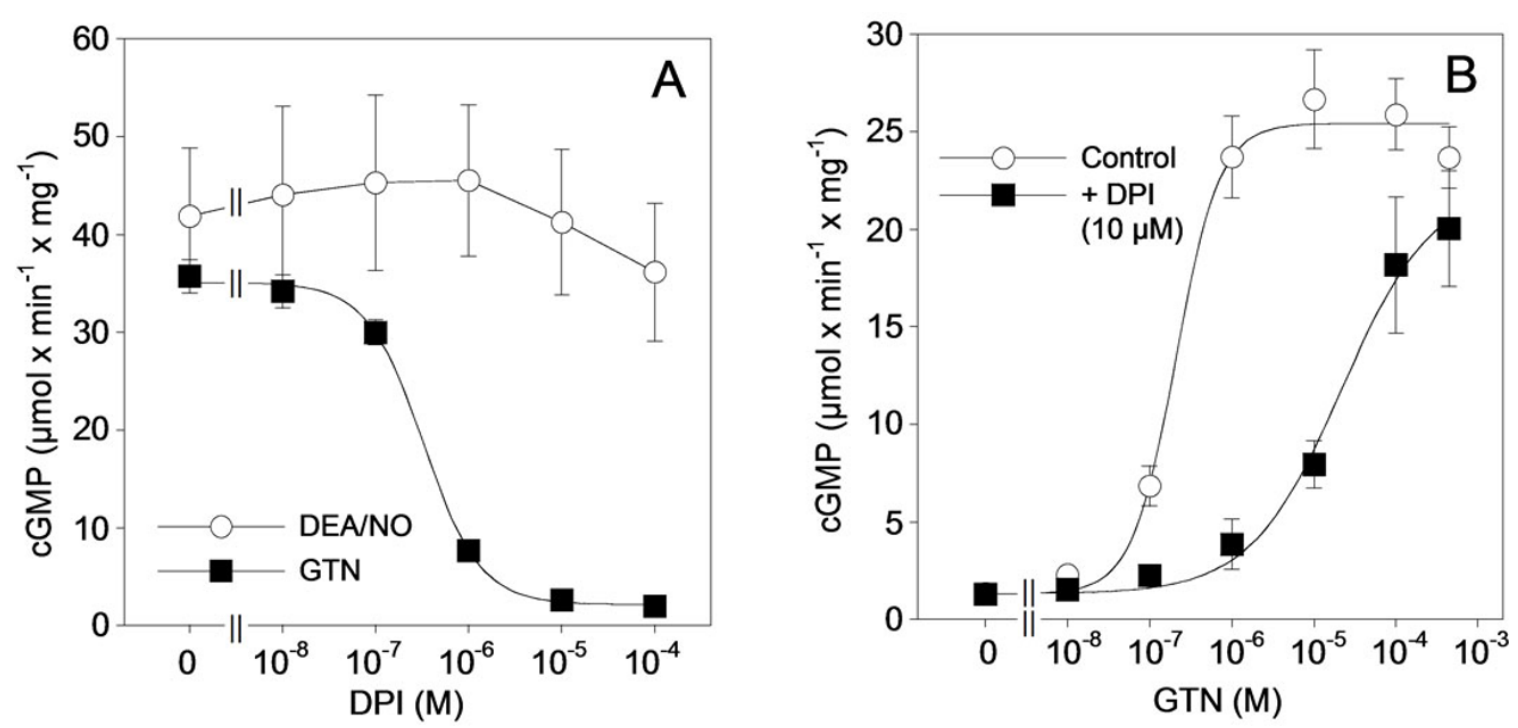

Figure 1 Effects of DPI on GTN-triggered activation of sGC in the presence of purified ALDH2. Purified sGC was incubated at $37^{\circ} \mathrm{C}$ for 10 min with $4 \mu \mathrm{g}$ of $\mathrm{ALDH} 2$ in the presence of $0.5 \mathrm{mM}[\alpha-32 \mathrm{P}] \mathrm{GTP}, 1,000 \mathrm{units} / \mathrm{ml} \mathrm{SOD}$, and $1 \mathrm{mM} \mathrm{NAD}{ }^{+}$with DPI, GTN or DEA/NO as indiacted, followed by isolation of ${ }^{32} \mathrm{P}-\mathrm{cGMP}$ and determination of radioactivity by liquid scintillation counting. A: Effects of the indicated concentrations of DPI on SGC activity determined in the presence of GTN or DEA/NO (1 $\mu \mathrm{M}$ each). B: Activation of sGC by increasing concentrations of GTN in the absnece and presence of $10 \mu \mathrm{M} \mathrm{DPI}$. The data are mean values \pm S.E.M. $(n=3-4)$.

\footnotetext{
* Correspondence: mayer@uni-graz.at

'Department of Pharmacology and Toxicology, Karl-Franzens-Universität

Graz, 8010 Graz, Austria

Full list of author information is available at the end of the article
} 


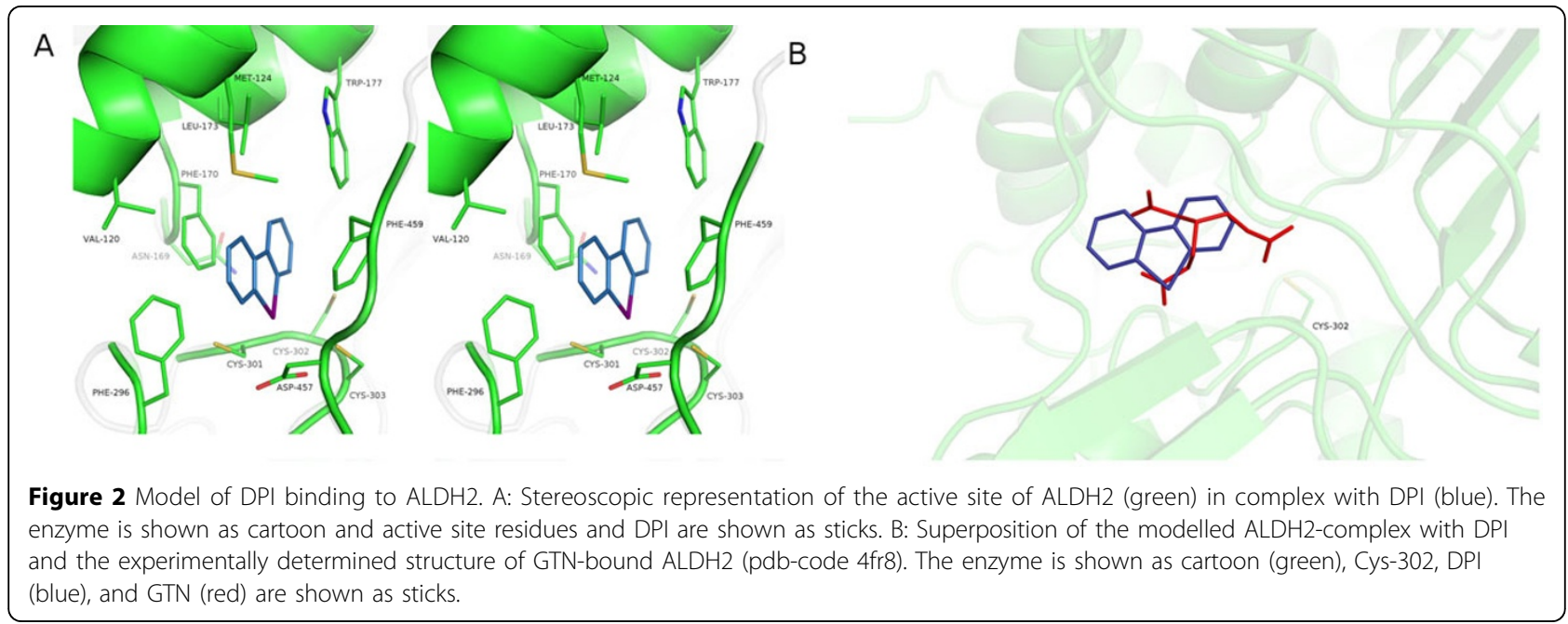

\section{Results}

DPI $(0.3 \mu \mathrm{M})$ inhibited the high affinity component of aortic relaxation to GTN without affecting the response to $\mathrm{NO}$, indicating that the drug interfered with GTN bioactivation. As shown in Figure 1A, DPI inhibited bioactivation of GTN $(1 \mu \mathrm{M})$ by ALDH2, assayed as activation of purified sGC, with an $\mathrm{IC}_{50}$ of $0.20 \pm 0.03 \mu \mathrm{M}$, whereas cGMP formation induced by the NO donor DEA/NO was not affected. DPI $(10 \mu \mathrm{M})$ caused a pronounced right-ward shift of the GTN concentration response (Figure 1B), indicating that the drug acts in a GTN-competitive manner. The effect on GTN bioactivation was accompanied by GTN-competitive inhibition of 1,2-glycerol dinitrate formation $\left(\mathrm{IC}_{50} 0.21 \pm 0.04 \mu \mathrm{M}\right.$ in the presence of $2 \mu \mathrm{M}$ GTN). DPI also inhibited the established dehydrogenase and esterase activities of ALDH2 with similar potency, again in a substrate-competitive manner. This was confirmed by molecular modeling, suggesting overlapping binding sites of DPI and GTN in the catalytic site of the enzyme (Figure 2). In contrast to ALDH2, ALDH1 and alcohol dehydrogenase were only partially (ALDH1) or not at all (ADH) inhibited by up to $0.1 \mathrm{mM}$ DPI.

\section{Conclusion}

The identification of DPI as potent ALDH2 inhibitor may have implications beyond the cardiovascular pharmacology of organic nitrates. A well established function of ALDH2 is detoxification of reactive aldehydes in liver and heart. NADPH oxidase activation has been implicated in both alcohol-induced liver injury and cardiac dysfunction. In view of the present results, showing that DPI potently inhibits the various enzymatic functions of ALDH2, it may be necessary to revise some of the earlier conclusions that are based on inhibitory effects of aryliodonium compounds.

\section{Authors' details}

'Department of Pharmacology and Toxicology, Karl-Franzens-Universität Graz, 8010 Graz, Austria. ${ }^{2}$ Department of Pharmacology and Toxicology, Ruhr-Universität Bochum, 44789 Bochum, Germany.

Published: 29 August 2013

\section{References}

1. Mayer $B$, Beretta $M$ : The enigma of nitroglycerin bioactivation and nitrate tolerance: News, views, and troubles. Br J Pharmacol 2008, 155:170-184.

2. McGuire JJ, Anderson DJ, Bennett BM: Inhibition of the biotransformation and pharmacological actions of glyceryl trinitrate by the flavoprotein inhibitor, diphenyleneiodonium sulfate. J Pharmacol Exp Ther 1994. 271:708-714.

doi:10.1186/2050-6511-14-S1-P49

Cite this article as: Neubauer et al:: Potent inhibition of nitroglycerin bioactivation by diphenyleneiodonium (DIP). BMC Pharmacology and Toxicology 2013 14(Suppl 1):P49.

\section{Submit your next manuscript to BioMed Central and take full advantage of:}

- Convenient online submission

- Thorough peer review

- No space constraints or color figure charges

- Immediate publication on acceptance

- Inclusion in PubMed, CAS, Scopus and Google Scholar

- Research which is freely available for redistribution 